\title{
Neuroeducation: understanding the brain to improve teaching
}

https://doi.org/10.24046/neuroed.20120101.1

\section{Steve MASSON ${ }^{1, *}$}

1 Université du Québec à Montréal

*Email : masson.steve@uqam.ca

Over the last ten years, a new research approach has been growing at an exponential rate. This approach, called neuroeducation, proposes to study problems faced by students and teachers as they learn and teach at an unexplored level of analysis: the cerebral level. Using brain imaging, neuroeducation tries not only to identify the brain mechanisms underlying school learning and teaching, but also to understand how knowing these mechanisms may contribute to the improvement of teaching practices.

The journal Neuroeducation was created to facilitate the further development of this new field of research by providing a place for researchers to evaluate and share new knowledge, i.e. a place where new data, methods and ideas can be submitted to a peer review process and published. For this reason, you will find papers in this journal that not only present experimental studies, but also experimental studies in preparation, theoretical studies proposing new hypotheses and models for teaching and learning, methodological discussions, reviews of literature, commentaries and book reviews.

In this first issue, you will find five papers. Three present research results. The first focuses on electroencephalographic data acquired in an authentic context, while the other two focus on the development of children's inhibition. A fourth paper proposes a model for teaching second, and foreign languages based on neuroimaging studies and the last is a commentary on the interest of using psychophysiological data to develop a better understanding of learning. 
To conclude, the remarkable work of editorial assistants (Geneviève Allaire-Duquette, Lorie-Marlène Brault Foisy, Jan-Sébastien Dion, Stephanie Lafortune, Élaine Turmel, and François Thibault) and researchers who contributed to the peer review process must be noted. The publication of this journal would not have been possible without their dedicated work. 